\title{
Dalang Anak dalam Pakeliran Wayang Kulit Purwa Gaya Surakarta
}

\author{
Junaidi $^{1}$ \\ Jurusan Pedalangan, Fakultas Seni Pertunjukan, Institut Seni Indonesia Yogyakarta
}

\begin{abstract}
Young Puppeteers on Solonese Wayang Performance. The aim of these research are to identify the structure of story, shadow puppet forms, and young puppeteer's motivations in pakeliran of Surakartanese purwa shadow puppets. This research applies multidiscipline approach, encompassing puppetry dramaturgy, iconography, physiognomy, and ethnochoreology, in order to study the stories, shadow puppets, and motivations. The pakeliran of purwa shadow puppets by young puppeteers performed in short time, short structure, skillful technique, and childish characteristic are a puppetry learning medium for children, appreciation of puppetry since early ages, and an effort of future art life continuity. In addition, the motivation of young puppeteer tends to be intrinsic which is based on the pleasant feeling in conducting non-commercial and profane activity.
\end{abstract}

Key words: shadow puppet, young puppeteer, wayang.

\section{Pendahuluan}

Pengertian pakeliran bukan semata-mata karena menggunakan peralatan kelir atau layar, tetapi lebih pada arti teatrikal yang berhubungan dengan penyajian peristiwa-peristiwa atau adegan-adegan dalam suatu kesatuan cerita atau lakon (Suyanto, 2007: 1), dimainkan oleh dalang selama \pm 9 jam atau semalam suntuk/sehari penuh, menampilkan satu lakon yang terdiri dari beberapa adegan, divisualkan dengan narasi/catur, gerakan boneka wayang/sabetan, dan didukung ilustrasi musik gamelan/karawitan pakeliran yang dimainkan oleh para musisi karawitan yang meliputi: pengrawit, pesindhèn, dan penggérong.

Pakeliran memiliki multi seni yaitu: seni drama (lakon), seni suara (catur dan sulukan), seni rupa (boneka wayang dan tata panggungan), seni tari (sabetan), dan seni sastra (bahasa pedalangan), sedangkan fungsinya juga berganda pula, yakni dapat ditampilkan dalam berbagai keperluan masyarakat seperti: upacara keagamaan, tontonan (hayatan), alat dakwah, alat propaganda, media penerangan, dan media hiburan (Soetarno, 2005: 214-215).

Wayang kulit purwa adalah boneka pipih terbuat dari kulit maésa (kerbau) atau lembu (sapi), sedangkan gaya Surakarta merupakan pengembangan dari wayang jaman terdahulu yaitu: jaman Kartasura, Mataram, Pajang, Demak, dan sebelumnya. Namun secara ekspilisit disebut gaya Surakarta baru sejak selesainya perjanjian Giyanti, yaitu pembagian wilayah Surakarta menjadi dua kerajaan yang kemudian diberi nama Surakarta Hadiningrat (Surakarta atau Solo) dan Ngayogyakarta Hadiningrat (Yogyakarta atau Mataram). Pembagian warisan kerajaan juga diikuti pembagian kesenian, salah satunya adalah seni wayang. Sampai sekarang kedua gaya wayang tersebut masih tetap bertahan, karena karya seni merupakan salah satu identitas budaya daerah yang paling tampak. Terbentuknya gaya seni Surakarta dan Yogyakarta erat kaitannya dengan kehidupan keraton masing-masing (Gustami, 2000: 95), sehingga secara fisik masih dapat dibedakan dan dipertahankan eksistensinya.

Wayang kulit purwa gaya Surakarta memiliki beberapa jenis yang berorientasi pada ukurannya, antara lain: (1) wayang kadung, yaitu boneka wayang berukuran lebih tinggi dan besar dibanding dengan jenis lainnya; (2) wayang padhalangan, yaitu boneka wayang berukuran lebih kecil dibanding dengan jenis wayang kadung, atau berukuran biasa, normal, atau umum; (3) wayang kidangkencanan, yaitu boneka wayang berukuran lebih kecil dibanding dengan jenis wayang padhalangan; dan (4) wayang kaper, yaitu boneka wayang berukuran sangat kecil atau lebih kecil dibanding dengan jenis wayang kidangkencanan.

1 Alamat korespondensi: Prodi Pedalangan ISI Yogyakarta. Jalan Parangtritis KM. 6,5 Sewon, Yogyakarta-55001. Telepon 0274-375380,e-mail: junaidi_skar@isi.ac.id. 
Keempat jenis wayang tersebut yang paling umum dipakai oleh para dalang dalam pakeliran adalah wayang padhalangan, sedangkan wayang kadung, kidangkencanan, dan kaper sangat langka keberadaannya.

Dahulu predikat dalang hanya dimiliki oleh para kaum laki-laki dewasa, karena tugasnya sebagai pemimpin upacara, bahkan sebagai guru yang mengajarkan suatu agama, sehingga atas pekerjaannya itu tidak mengharapkan bayaran (sepi ing pamrih ramé ing gawé). Namun selanjutnya dalang bekerja sebagai pemain pertunjukan, salah satu tugas yang dilakukan adalah mengatur honorarium yang diterima dari pekerjaannya itu, dengan kata lain bahwa pekerjaan dalang sebagai mata pencaharian (Sastroamidjojo, 1964: 90). Perkembangan selanjutnya predikat dalang juga dimiliki oleh anak-anak yaitu dalang anak/ kecil/bocah. Menurut Sarlito Wirawan Sarwono bahwa kategori anak, yaitu seseorang yang berusia sekitar 7-14 tahun (Sarwono, 2005: 21). Oleh karena itu, maka yang dimaksud dalang anak adalah seorang dalang yang umurnya sekitar 7-14 tahun, yang secara tingkat pendidikan berada pada level pendidikan Sekolah Dasar (SD) dan awal Sekolah Menengah Pertama (SMP). Secara fisik anak pada usia tertentu mempunyai ukuran tinggi badan tertentu pula, sesuai dengan tingkat perkembangannya (Hurlock, 1978: 117). Secara kejiwaan anak-anak dalam usia tersebut bersifat kekanakan yang orientasinya melakukan kegiatan belajar dan bermain.

Tampilnya dalang anak menjadi penyaji pakeliran wayang kulit purwa gaya Surakarta, merupakan fenomena budaya yang menarik dan penting untuk dikaji, karena dianggap sesuatu yang istimewa degan kata lain nggumunaké, bahkan mendapat predikat menjila, untuk ukuran anak yang biasanya hanya melakukan kegiatan belajar di tingkat rendah dan bermain, tetapi sudah dapat menampilkan suatu pertunjukan seperti yang ditampilkan oleh dalang dewasa atau tua (kasepuhan). Secara tradisi bahwa pakeliran wayang kulit purwa gaya Surakarta telah dirumuskan yaitu: regu (rasa luhur atau wibawa), greget (rasa semangat), sem (rasa romatis), nges (rasa sedih atau trenyuh), renggep (tetap bersemangat atau ajeg), antawacana (narasinya bagus sesuai dengan rasa gending dan bentuk wayang), cucut (rasa humoris), unggah-ungguh (memiliki etika), tutuk (jelas ucapannya), dan trampil (lihai mengatur dan memainkan wayang) (Nojowirongko, 1960: 57). Tentu saja kondisi fisik dan kejiwaan orang tua dan anak berbeda, sehingga kenyataan ini memunculkan pertanyaan mengapa pakeliran wayang kulit purwa gaya Surakarta oleh dalang anak? Untuk menjawab pertanyaan ini dilakukan penelitian terhadap pakeliran wayang kulit purwa yang dilakukan oleh dalang anak. Mengingat luasnya cakupan unsur-unsur pakeliran, maka pembahasan ini dibatasi dua unsur utama yaitu cerita/lakon dan wayang/boneka.

\section{Lakon yang ditampilkan oleh Dalang Anak}

Berdasarkan data yang dapat ditemukan di berbagai pementasan wayang kulit purwa yang dilakukan oleh para dalang anak, terdapat beberapa macam dan jenis lakon yang telah ditampilkan. Jumlahnya masih sedikit, bahkan terdapat satu macam lakon yang ditampilkan oleh beberapa dalang anak. Namun demikian juga sebaliknya ada dalang yang menampilkan beberapa macam lakon. Rentangan waktu setiap lakon sekitar 3/4 - 1 jam atau 45-60 menit, sehingga dalam rentangan waktu 9 jam dapat menampilkan 9-13 lakon.

Tabel 1. Nama dan jenis lakon dalang anak.

\begin{tabular}{|c|c|c|c|}
\hline No. & Nama lakon & Jenis lakon & Dalang \\
\hline 1. & Séna Bumbu & Patèn & $\begin{array}{l}\text { Adam Gifari dan Yudhistira Nurdian } \\
\text { Qurrota }\end{array}$ \\
\hline 2. & Anoman Dhuta & Dhutan & $\begin{array}{l}\text { Anggit Laras Prabowo, } \\
\text { Rafif Pujasmara, Arko Kilat Kusumaningrat, } \\
\text { dan Yusstanza Razali }\end{array}$ \\
\hline 3. & Babat Alas Wanamarta & Babatan & $\begin{array}{l}\text { Prasetyo Dunung, Panggalih Pamungkas } \\
\text { Pulung Wicaksana Nugraha, Canggih Tri } \\
\text { Atmojo Krisno, dan Anggit Laras Prabowo }\end{array}$ \\
\hline
\end{tabular}




\begin{tabular}{|c|c|c|c|}
\hline 4. & Gathutkaca Lahir/Jèdhi & Lahiran & $\begin{array}{l}\text { Doni Siswanto, Rafif Pujasmara, Wisnu } \\
\text { Septiawan, dan Gadhing Panjalu Wijanarko } \\
\text { Putro }\end{array}$ \\
\hline 5 & Kangsa Adu Jago & Kraman & Ananda Magistra Yoga Utama \\
\hline 6. & Aji Narantaka & Nugraha & $\begin{array}{l}\text { Krisna, Bayu Gunawan, Sindhunata Gesit } \\
\text { Widiharto, dan Doni Siswanto }\end{array}$ \\
\hline 7 & Kresna Dhuta & Dhutan & Galang dan Adam Gifari \\
\hline 8. & Palguna-Palgunadi & Patèn & $\begin{array}{l}\text { Pandu Gandang Sasongko dan Pandu } \\
\text { Gandhang Sasongko }\end{array}$ \\
\hline 9. & Kresna Gugah & Nugraha & Arvian Aditama \\
\hline 10. & Wahyu Cakraningrat & Wahyu & Pulung Wicaksana Nugraha \\
\hline 11. & Nggeguru/Déwa Ruci & Maguru & $\begin{array}{l}\text { Rakha Alfirdaus Hikmatyar, Guntur Gagat } \\
\text { Tri Putranto, dan Amar Pradhopo Zedha } \\
\text { Beviantyo }\end{array}$ \\
\hline 12. & Brajadenta Mbaléla & Kraman & Bian Diva Nurisa \\
\hline 13. & Adon-adon Rajamala & Kraman & Canggih Tri Atmaja Krisno \\
\hline 14. & Wiratha Parwa & Kraman & Ananda Magistra Yoga Utama \\
\hline 15. & Guwarsa-Guwarsi & Malihan & $\begin{array}{l}\text { Rizky Fauzyah, Moni Dwi Rahayu, Bimo } \\
\text { Sinung Widagdo }\end{array}$ \\
\hline 16. & Prawirayuda & Kraman & Danan Wisnu Pratama \\
\hline 17. & Gathutkaca Pinilih & Wabyu & Dhimas Anggoro Putro \\
\hline 18. & Puntadéwa Tandang & Kraman & Dwi Adi Nugroho \\
\hline
\end{tabular}

Sumber: Daftar peserta festival dalang bocah tahun 2005, temu dalang cilik nusantara III tahun 2007, dan 2009.

Lakon Séna Bumbu adalah jenis lakon patèn atau kematian yaitu matinya raja raksasa dari Ekacakra Prabu Bakasura oleh Raden Bratasena. Lakon ini ditampilkan oleh Adam Gifari seorang anak laki-laki berusia 10 tahun, putra penyanyi Dangdut Haji Roma Irama dengan Gita Andini Saputri, dari Donohudan, Ngemplak, Boyolali, dalam bentuk pakeliran ringkas berdurasi waktu sekitar 45 (empat puluh lima) menit atau 3/4 (tiga perempat) jam, pada tanggal 24 Juli 2008 di Pendapa Padepokan Seni Sarotama Jalan Gambiranom 13, Gunungsari Benowo, Ngringo, Jaten, Karanganyar, Surakarta, dalam rangka gladi bersih untuk mengikuti Festival Dalang Bocah Tingkat Nasional di Taman Mini Indonesia Indah Jakarta tahun 2008. Istilah pakeliran ringkas berdurasi waktu sekitar 45 menit tidak tepat, karena secara konvensi pakeliran ini berdurasi waktu 3-5 jam. Dalang lain yang menyajikan lakon ini adalah Yudhistira Nurdian Qurrota seorang anak laki-laki berusia 8 tahun, putra sulung Bapak Sarsidi, dari Wirun, Mojolaban,
Bekonang, Sukoharjo, dalam bentuk pakeliran ringkas, pada tanggal 24 September 2005, dalam rangka Fesival Dalang Bocah I Nasional 2005, di Pendapa Taman Budaya Jawa Tengah Jalan Ir. Sutami 57 Surakarta. Isi ceritanya yaitu Prabu Bakasura raja raksasa yang bersifat kanibal. Pada setiap kesempatan tertentu rakyatnya harus bergilir menyerahkan manusia untuk dijadikan santapannya. Pada saat itu, jatuh giliran Resi Ijrapa yang diwakili oleh Bima, tetapi justru raja raksasa itu binasa ditangan Bima.

Lakon Anoman Dhuta adalah jenis lakon dhutan atau utusan, ditampilkan oleh Anggit Laras Prabowo, seorang anak laki-laki berusia 9 tahun putera bungsu Purwadi, kepala desa Tunggulrejo, Kecamatan Jumantono, Kabupaten Karanganyar. Lakon Anoman Dhuta disajikan dalam bentuk pakeliran ringkas dengan durasi waktu sekitar 45 (empat puluh lima menit) atau $3 / 4$ (tiga perempat) jam, di Pendapa Padepokan Seni Sarotama Jalan Gambiranom 13, Gunungsari Benowo, Ngringo, 
Jaten, Karanganyar, Surakarta, pada tanggal 24 Juli 2008. Lakon ini juga ditampilkan oleh dalang lain seperti: Rafif Pujasmara ( 9 tahun), dalam rangka Fesival Dalang Bocah I Nasional 2005, di Pendapa Taman Budaya Jawa Tengah Jalan Ir. Sutami 57 Surakarta, dan Arko Kilat Kusumaningrat seorang anak laki-laki putra Eko Wahyu Prihantoro dan Sri Hartini, dari Puncak Solo B3 Mojosongo, Surakarta, pada acara Temu Dalang Cilik Nusantara III tanggal 15-20 Juli 2009 di Pendapa Taman Budaya Jawa Tengah Jalan Ir. Sutami 57 Surakarta. Isi ceritanya yaitu mengutus Anoman menjadi duta mencari titik jejak keberadaan Dewi Sinta. Berbagai rintangan dapat dilalui dan akhirnya dapat ditemukan keberadaan Dewi Sinta, yaitu berada di Taman Argasoka wilayah Negara Alengka. Untuk menandai ketemunya Anoman dengan Dewi Sinta, maka Anoman menyerahkan cincin Sotyaludira pembawaan dari Prabu Rama, sedangkan Dewi Sinta menyerahkan tusuk sanggul Cundhamanik untuk disampaikan kepada suaminya.

Babat Alas Wanamarta adalah jenis lakon babatan atau pembukaan lahan baru, ditampilkan oleh Prasetyo Dunung Panggalih (12 tahun), pada tanggal 24 Juli 2008 di Pendapa Padepokan Seni Sarotama. Isi cerita ini mengisahkan para Pandawa (Puntadewa, Bratasena, Premadi, Pinten, dan Tangsen) melakukan pembersihan hutan Wanamarta untuk dijadikan kerajaaan. Berbagai rintangan yang menghadang, tetapi dapat diatasi dan akhirnya berhasil membangun kerajaan yang indah diberi nama Negara Amarta.

Gathutkaca Lahir atau Jabang Tetuka atau Gathutkaca Jèdhi adalah jenis lakon lahiran atau kelahiran, ditampilkan dalam pakeliran singkat berdurasi waktu sekitar 45 (empat puluh lima) menit atau 3/4 (tiga perempat) jam, oleh dalang Doni Siswanto seorang anak laki-laki berusia 11 tahun, putera Supaya seorang tukang bangunan dari Dukuh Lor, Pakahan, Jogonalan, Klaten, pada tanggal 24 Mei 2008 di Gandok Seni Pondok Tingal Hotel, Borobudur, Kabupaten Magelang. Lakon ini juga ditampilkan oleh empat dalang lainnya seperti: Rafif Pujasmara (12 tahun) pada tanggal 21 Agustus 2005, di Pendapa Padepokan Seni Sarotama. Wisnu Septiawan (11 tahun), Gadhing Panjalu Wijanarko Putro (10 tahun), dan Cendikia Ashmatuka Srihascaryasmoro (8 tahun), pada Temu Dalang Cilik Nusantara III tanggal
15-20 Juli 2009 di Pendapa Taman Budaya Jawa Tengah Jalan Ir. Sutami 57 Surakarta. Isilengkapnya menceritakan masa kecil Gatutkaca yang berhasil membinasakan raja raksasa Prabu Kalapracona di negara Gilingwesi yang menginginkan Batari Supraba sebagai isterinya. Untuk menyiapkan Gatutkaca yang masih kecil tersebut dilakukan penggemblengan fisik di Kawah Candradimuka. Akhirnya wujud Gatutkaca berubah menjadi gagah perkasa dan sakti mandraguna sehingga dapat membunuh musuh dewa tersebut.

Lakon Kangsa Adu Jago adalah jenis lakon kraman, berisi tentang serangan Raden Kangsadewa terhadap pemerintahan negara Mandura dengan cara mengadakan pertandingan adu manusia. Lakon ini disajikan dalam bentuk pakeliran padat berdurasi waktu sekitar 60 (enam puluh) menit atau 1 (satu) jam, oleh dalang bocah Ananda Magistra Yoga Utama, seorang anak lakilaki berusia 11 tahun, putera almarhum Waridi dosen Jurusan Karawitan, Institut Seni Indonesia Surakarta, pada tanggal 11 Oktober 2008 di Kadipaten Kidul, Kebondalem Kidul, Prambanan, Klaten.

Kresna Dhuta adalah jenis lakon dhutan atau utusan, berisi tentang perjalanan Prabu Kresna ke negara Ngastina sebagai utusan Pandawa untuk meminta kembali negara Indraprasta yang dikuasai oleh para Kurawa dalam permainan dadu. Lakon ini ditampilkan dalam bentuk pakeliran ringkas oleh dalang anak bernama Galang, seorang anak laki-laki berusia 9 tahun dari Dusun Dukuh Lor, Desa Pakahan, Kecamatan Jogonalan, Kabupaten Klaten, Propinsi Jawa Tengah. Dalang anak lainnya yang menampilkan lakon ini adalah Magistra Yoga Utama (11 tahun) dari Perum Subur Makmur Jalan Lawu, Ngringo, Jaten, Karanganyar, pada saat Temu Dalang Cilik Nusantara III tanggal 16 Juli 2009 di Taman Budaya Surakarta.

Aji Narantaka adalah jenis lakon patèn atau kematian, yaitu berisi perkelahian antara Raden Dursala anak Raden Dursasana melawan Raden Gatutkaca putera Raden Werkudara. Lakon ini disajikan oleh Doni Siswanto dalam bentuk pakeliran singkat, berdurasi waktu sekitar 30 (tiga puluh) menit atau $1 / 2$ (setengah) jam.

Palguna-Palgunadi adalah jenis lakon patèn yang berisi kisah seorang raja dari negara Pranggelung Prabu Palgunadi, yang menginginkan untuk menjadi pemanah ulung. Lakon ini ditam- 
pilkan oleh dalang anak bernama Pandu Gandhang Sasongko (8 tahun) dari Mojo Wetan, Sragen, dalam bentuk pakeliran padat durasi waktu \pm 1 (satu) jam, pada Festival Dalang Bocah I tanggal 26 September 2005 di Pendapa Taman Budaya Jawa Tengah, dan tanggal 14 Juli 2009, pada Temu Dalang Cilik Nusantara III, di Pendapa Taman Budaya Jawa Tengah. Ketika pementasan kedua dengan lakon yang sama ini Pandu sudah berusia 12 tahun.

Kresna Gugah adalah jenis lakon nugraha yang berisikisahPrabuKresnayangsedangmelaksanakan tapa tidur, untuk mendapatkan wangsit atau bisikan dari dewa yang benar dan tepat tentang ramalan adanya perang Baratayuda. Pandawa dan Kurawa berlomba untuk membangunkan Prabu Kresna dalam rangka untuk mencari dukungan. Pada akhirnya Pandawa yang didukung oleh Kresna, sedangkan Kurawa mendapatkan prajurit Dwarawati yang berjumlah sangat banyak. Lakon ini ditampilkan oleh dalang anak Arvian Aditama (8 tahun) dari Sragen, dalam bentuk pakeliran padat berdurasi waktu \pm 1 (satu) jam, tanggal 26 September 2005 pada acara Festival Dalang Bocah I di Pendapa Taman Budaya Jawa Tengah.

Wahyu Cakraningrat adalah jenis lakon wahyu yang berisi kisah tentang turunnya anugerah Wahyu Cakraningrat dari dewa. Para ksatria dari Pandawa (Abimanyu) dan Astina (Lesmanamandrakumara) saling memperebutkan wahyu tersebut, dan ternyata Abimanyu yang mendapatkannya. Pihak Kurawa merasa kecewa, kemudian menyerang Abimanyu untuk merebut wahyu tersebut. Peperangan terjadi antara pihak Pandawa melawan Kurawa, yang pada akhirnya dimenangkan oleh pihak Pandawa. Lakon ini ditampilkan oleh dalang anak Pulung Wicaksana Nugraha (10 tahun) dari Kuncen, Klaten, dalam bentuk pakeliran padat dengan durasi waktu \pm 1 (satu) jam, pada tanggal 27 September 2005, dalam rangka Festival Dalang Bocah I, di Pendapa Taman Budaya Jawa Tengah.

Nggeguru/Déwa Ruci adalah jenis lakon lebet yang isinya menceritakan tentang usaha Raden Bratasena untuk mendapatkan ilmu sejati. Oleh gurunya Resi Durna ia harus mencari syarat lebih dahulu yaitu Kayu Gung Susuhing Angin ke hutan Wreksamuka. Sesampai di tempat yang dituju ia tidak mendapatkan yang dimaksud, tetapi ketemu dengan Batara Indra dan Batara Bayu. Kemudian
Resi Durna memerintahkan lagi agar Bratasena mencari Banyu Suci Perwitasari ke samodra Minangkalbu. Di tempat itu, Bratasena dapat membunuh seekor naga Nemburnawa dan dapat bertemu dengan Dewa Ruci yaitu Sang Guru Sejati. Lakon ini ditampilkan oleh Amar Pradhopo Zedha Bevianto (9 tahun), dari Kranggan, Makam Haji, Kartosuro, Sukoharjo, dalam bentuk pakeliran padat dengan durasi waktu \pm 1 (satu) jam, pada Temu Dalang Cilik Nusantara III 16 Juli 2009 di Pendapa Taman Budaya Jawa Tengah.

Brajadenta Mbaléla adalah jenis lakon kraman berisi tentang ketidakpuasan Raden Brajadenta terhadap pengangkatan keponakannya Raden Gatutkaca sebagai raja di negara Pringgondani. Menurutnya yang berhak menerima warisan menjadi raja adalah anak laki-laki dari keturunan Prabu Tremboko. Hal ini diketahui oleh Kurawa, sehingga amarahnya semakin membara karena mendapat dukungan dari Sangkuni beserta keponakan-keponakannya. Perang terjadi antara Gatutkaca dengan Brajadenta yang pada akhirnya menimbulkan kematian kedua pamannya yaitu Brajadenta dan Brajamusti. Lakon ini ditampilkan oleh dalang anak Bian Diva Nurisa (10 tahun) dari Surakarta, dalam bentuk pakeliran padat dengan durasi waktu \pm 1 (satu) jam, pada tanggal 16 Juli 2009, pada Temu Dalang Cilik Nusantara III 16 di Pendapa Taman Budaya Jawa Tengah.

Adon-adon Rajamala adalah jenis lakon kraman, berisi tentang upaya merebut negara Wirata oleh Patih Kencakarupa, dengan cara mengadakan keramaian pertandingan adu manusia. Jago dari pihak Raden Kencaka adalah Rajamala, sedangkan jago dari pihak Prabu Matswapati adalah Jagal Abilawa. Usaha Patih Kencaka tidak berhasil, karena jagonya berhasil dikalahkan oleh Jagal Abilawa. Patih Wirata ini mengamuk akan membunuh Jagal Abilawa, tetapi justru dapat dibunuh oleh jago Wirata yang dibantu oleh Wrehatnala. Lakon ini ditampilkan oleh dalang anak Canggih Triatmojo Krisno (9 tahun), dari Perum Subur Makmur Jalan Merapi No. 5 Ngringo, Jaten, Karanganyar, pada tanggal 16 Juli 2009, dalam bentuk pakeliran padat dengan durasi waktu \pm 1 (satu) jam, pada Temu Dalang Cilik Nusantara III, di Pendapa Taman Budaya Jawa Tengah.

Wiratha Parwa adalah jenis lakon kraman, berisi tentang penyerbuan negara Wirata oleh 
para senopati negara Astina, di bawah pimpinan Prabu Karna, Resi Bisma, Pendeta Durna, Prabu Duryudana sendiri, dengan dibantu raja Trigarta Prabu Susarma. Alasan penyerbuan adalah kematian Patih Kencakarupa, Rupakenca, dan Rajamala yang dianggap kekuatan Wirata telah rapuh. Di samping itu, dicurigai sebagai tempat persembunyian para Pandawa. Namun demikian serangan Kurawa dan Susarma dapat dilumpuhkan oleh Wrehatnala dan Jagalabilawa. Lakon ini ditampilkan oleh dalang anak Magistra Yoga Utama (11 tahun), dalam bentuk pakeliran padat dengan durasi waktu \pm 1 (satu) jam, tanggal 16 Juli 2009, pada Temu Dalang Cilik Nusantara III, di Pendapa Taman Budaya Jawa Tengah.

Guwarsa-Guwarsi adalah jenis lakon malihan, mengisahkan perebutan Cири Manik Astagina oleh ketiga putera Resi Gotama di pertapan Grastino. Cирu ini milik Dewi Anjani pemberian ibunya Dewi Windradi. Akhirnya cupu dibuang oleh Resi Gotama ke tengah hutan, berubah wujud menjadi 'Sendang Sumala' artinya kolam berisi air berbisa. Ketiga putera dari Grastino ini tidak memperdulikan, lalu terjun ke sendang dan berubah wujud menjadi kera. Lakon ini ditampilkan oleh dalang anak Rizky Fauzyah (13 tahun), dalang anak wanita dari Pucangsawit Rt. 02 RW XI, Jebres, Surakarta, tanggal 16 Juli
2009, pada Temu Dalang Cilik Nusantara III, di Pendapa Taman Budaya Jawa Tengah, dan Moni Dwirahayu dalam bentuk pakeliran padat dengan durasi waktu \pm 1 (satu) jam, tanggal 17 Desember 2009, pada acara festival dalang bocah tahun 2009 di Gedung Pewayangan Kautaman, Taman Mini Indonesia Indah Jakarta.

Mengamati ragam lakon yang ditampilkan oleh dalang anak di atas, kaitannya dengan tuntutan kualitas penyajian lakon wayang yang harus memenuhi standar yaitu: trep (sesuai antara waktu dengan lakon), tutug (selesai atau tuntas), mungguh (sesuai dengan tata aturan), kempel (terpadu jalinan antar unsur), dan mulih (terjawab) (Sumanto dalam Soetarno, 2007: 117-122), ditemukan ketidak tercapainya tuntunan tersebut secara penuh. Pertama mengenai tuntutan trep, bahwa lakon wayang secara tradisi dibingkai 9 jam, jikalau terjadi kelebihan atau kekurangan dengan alokasi waktu yang ditentukan dianggap cacat, yakni jika lebih dikatakan karahinan (kesiangan), dan kalau kurang disebut kebogélan (belum saatnya). Dengan demikian, maka trepnya untuk penyajian lakon wayang oleh dalang anak lebih sesuai \pm 1 jam dan bentuknya disebut dengan pakeliran pendek atau cekak, sedangkan adegannya berjumlah 16 macam yang terbagi menjadi tiga bagian atau pathet.

Tabel 2. Alokasi pembagian waktu pertunjukan.

\begin{tabular}{lll}
\hline No. & Pathet Nem & Alokasi Waktu \pm 20 Menit \\
\hline 1. & Jejer & \pm 7 menit \\
2. & Budhalan jejer & \pm 3 menit \\
3. & Adegan sabrang & \pm 4 menit \\
4. & Budhalan sabrang & \pm 3 menit \\
5. & Prang gagal & \pm 3 menit \\
\hline & Pathet Sanga & Alokasi Waktu \pm 20 Menit \\
\hline 6. & Adegan sanga kapisan & \pm 6 menit \\
7. & Budhalan sanga kapisan & \pm 3 menit \\
8. & Adegan sintrèn & \pm 4 menit \\
9. & Budhalan sintrèn & \pm 3 menit \\
10. & Prang kembang & \pm 4 menit \\
\hline & Pathet Manyura & Alokasi Waktu \pm 20 Menit \\
\hline 11. & Adegan manyura kapisan & \pm 4 menit \\
12. & Budhalan manyura kapisan & \pm 3 menit \\
13. & Adegan manyura kaping kalih $\quad$ Budhalan & \pm 4 menit \\
14. & manyura kaping kalih & \pm 3 menit \\
15. & Prang brubuh & \pm 3 menit \\
16. & Adegan tancep kayon & \pm 3 menit \\
\hline
\end{tabular}


Kedua tutug artinya selesai atau tuntas, yakni suatu lakon wayang harus dapat menampilkan perjalanan lakon dimulai dari introduksi (pembukaan atau awal terjadinya lakon), memasuki isi (prmbahasan atau pemecahan lakon), dan berakhir konklusi (kesimpulan atau keputusan akhir lakon), dengan alur berpikir : mencari latar belakang atau motivasi tokoh sentral dalam lakon untuk melakukan tindakan, proses tindakan tokoh sentral dalam lakon dengan menghadapi berbagai persoalan, dan penyelesaian permasalahan yang dilakukan tokoh sentral (Sumanto dalam Soatarno, 2005: 119). Berpijak pada lakon-lakon yang ditampilkan oleh dalang anak tersebut di atas, kaitannya dengan konsep tutug yang disampaikan oleh Sumanto, ada beberapa lakon saja yang dapat dikuasai oleh dalang anak, seperti misalnya lakon GuwarsaGuwarsi yakni berisi perebutan mainan antara ketiga anak-anak Resi Gotama, karena persoalan yang dibicarakan masalah alat permainan (Cupu Manikastagina), sedangkan untuk lakon Kresna Dhuta kiranya sulit diselesaikan oleh dalang anak, karena persoalan yang dibicarakan adalah politik perebutan kekuasaan antar keturunan Barata (Baratayuda). Persoalan seperti ini kiranya belum saatnya dipecahkan oleh anak, karena fantasi dunia anak dalam rentangan ini berorientasi pada kisah-kisah dongeng dan masuk akal (Zulkifli, 2006: 56).

Ketiga, mungguh artinya logis sesuai dengan aturan atau norma pakeliran yakni catur dan sabet yang ditampilkan tidak boleh keluar dari norma dan aturan pakeliran. Dalam hal ini para dalang anak masih mengikuti norma dan aturan pakeliran yang diajarkan oleh pelatih, karena penampilannya dipandu oleh naskah yang diciptakan oleh pelatihnya, sehingga peran pelatih untuk tetap mempertahankan norma dan aturan pakeliran sangat dominan.

Keempat, kempel maksudnya terpadu jalinan antar unsur yang terdiri atas: adegan, tokoh, alur, seting, suasana, tema, dan amanat. Melihat lakon yang ditampilkan oleh dalang anak di atas lebih banyak yang tidak kempel, karena tokoh, tema, seting, suasana, dan amanatnya menampilkan dunia orang deawasa, sehingga kurang sesuai dengan atmosfir dunia kekanakan.

Kelima, mulih maksudnya terjawab lakon yang ditampilkan oleh dalang anak. Namun demikian, jika melihat judul-judul lakon yang ditampilkan dengan kenyataan yang disampaikan tidak terjawab, seperti misalnya: lakon Déwa Ruci tidak memunculkan tokoh Dewa Ruci yang mengajarkan pengetahuan asal-mula dan tujuan hidup (sangkan paraning dumadi) sebagai jawaban lakon tersebut, tetapi yang ditampilkan terkonsentrasi pada adegan Bima berperang dengan raksasa Rukmuka dan Rukmakala.

\section{Wayang Kulit Purwa yang Ditampilkan oleh Dalang Anak \\ Ukuran Wayang}

Boneka wayang yang ditampilkan oleh dalang anak adalah boneka wayang kulit purwa gaya Surakarta, milik para dalang atau koleksi di luar istana Kasunanan dan Mangkunagaran, bahkan ada beberapa dalang anak yang sengaja menyediakan tokoh-tokoh wayang sendiri (wayang gawan). Sebagai contoh Anggit Laras Prabowo (8 tahun) menggunakan wayang kulit purwa tradisi milik lembaga tersebut, yaitu seperangkat wayang padhalangan. Wayang padhalangan tersebut ditampilkan sebagai tokoh dalam lakon, simpingan, dhudhahan, dan ricikan. Doni Siswanto (11 tahun) dalam lakon Aji Narantaka, memakai wayang milik Nuryanto Putra yaitu wayang jenis kidangkencanan dan wayang padhalangan koleksi Ki Suwito dari Klaten. Wayang kidangkencanan ditampilkan khusus untuk lakon, sedangkan wayang padhalangan digunakan sebagai simpingan, dhudhahan, dan ricikan. Pada kesempatan lain dalang anak ini juga menggunakan wayang ukuran padhalangan secara keseluruhan baik untuk lakon, simpingan, dhudhahan, dan ricikan. Adam Gifari (10 tahun) menggunakan wayang simpingan, dhudhahan, dan ricikan sama seperti yang dipakai oleh Anggit Laras Prabowo, tetapi untuk wayang lakon ditemukan tokoh ButaRaton ukuran khusus sebagai Prabu Baka. Buta Raton ini kedua tangannya dapat digerakkan, atau istilahnya 'buta tangan loro', maksudnya boneka wayang raksasa raja yang kedua tangannya dapat digerakkan. Biasanya wayang raksasa hanya dapat digerakkan satu tangannya, yaitu tangan depan (tangan ngarep), sedangkan satu tangannya di belakang malangkerik atau berkacak pinggang tanpa diberi persendian (gegel) yang disatukan dengan tubuhnya. Ukuran khusus wayang Buta Raton tangan dua yang dimaksud adalah seukuran 
dengan wayang Boma atau ukuran magak. Menurut Adam Gifari, dipakainya boneka wayang Buta Raton berukuran lebih kecil dari yang biasa, agar ringan untuk digerakkan. Dengan demikian, maka dilakukan pengurangan ukuran tokohtokoh wayang yang dianggap berukuran besar, agar dalang anak tersebut tidak merasa keberatan, sehingga tingkat ketrampilannya bisa tercapai dengan mudah. Namun demikian, ada beberapa anak yang tetap menggunakan wayang berukuran biasa, seperti Wuwus Nanang Galih Carito.

Magistra Yoga Utama (10 tahun) dalam lakon Kangsa Adu Jago menggunakan wayang ukuran padhalangan secara keseluruhan, baik yang ditampilkan maupun yang disimping, yaitu milik Ki Bambang Suwarno dari Surakarta. Pemakaian wayang ini ada kaitannya dengan dalang dewasa, karena pertunjukan wayang tersebut dilakukan oleh dua generasi dalang yaitu dalang anak dan dalang dewasa. Dengan demikian, maka boneka wayang kulit purwa yang ditampilkan oleh dalang anak, ada yang sama dan ada yang berbeda dengan yang dipakai oleh dalang dewasa atau tua.

Secara garis besar bahwa wayang kulit purwa yang ditampilkan oleh dalang anak dapat dikategorikan menjadi tiga jenis yaitu: (1) jenis wayang padhalangan biasa, yakni boneka wayang berukuran biasa seperti yang dipakai oleh dalang dewasa; (2) wayang kidangkencanan, yakni boneka wayang yang berukuran lebih kecil dibanding jenis wayang padhalangan; dan (3) wayang padhalangan yang diperkecil untuk tokoh-tokoh tertentu, yakni tokoh-tokoh berukuran magak (sak Gathutkaca), gedhé (sak Buta Patihan), dan paling gedhé (sak Buta Raton). Sebagai contoh ketiga jenis wayang kulit purwa yang digunakan oleh dalang anak dalam berbagai kesempatan pementasan dapat dilihat pada gambar-gambar di bawah.

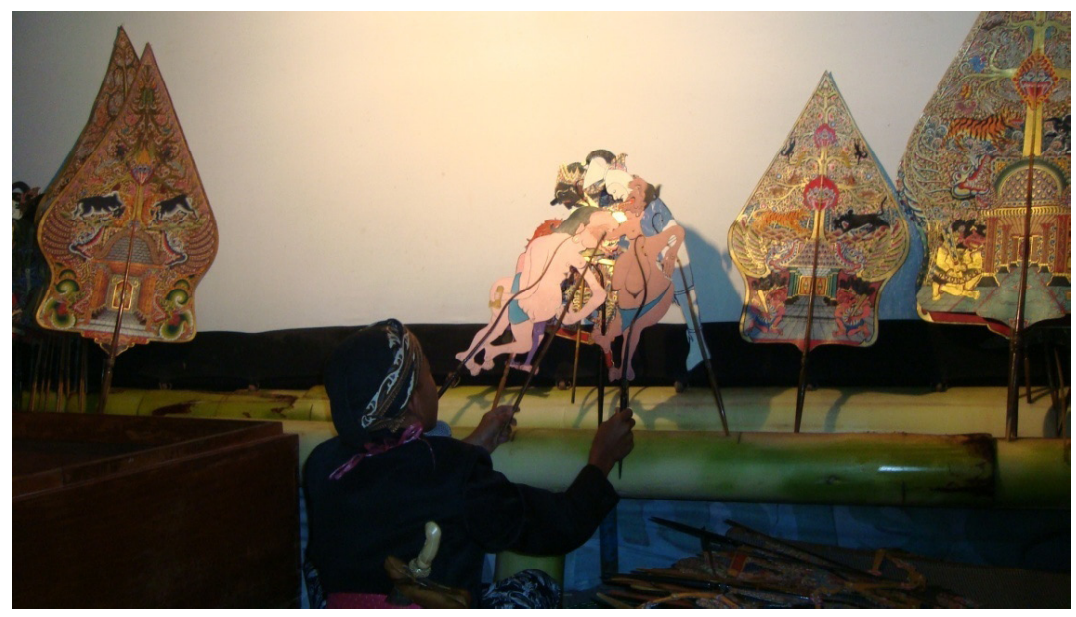

Gambar 1. Dalang anak Doni Siswanto menggunakan wayang kidangkencanan dan wayang padhalangan dalam satu pementasan (Foto: Junaidi, 2009).

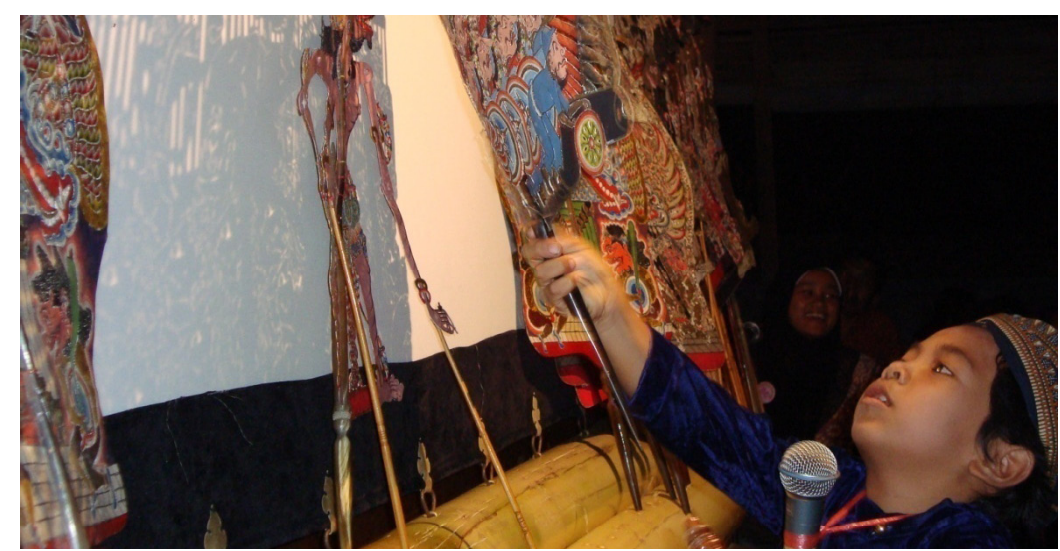

Gambar 2. Dalang anak Anggit Laras Prabowo menggunakan wayang padhalangan, koleksi Padepokan Seni Sarotama (Foto: Junaidi, 2008). 


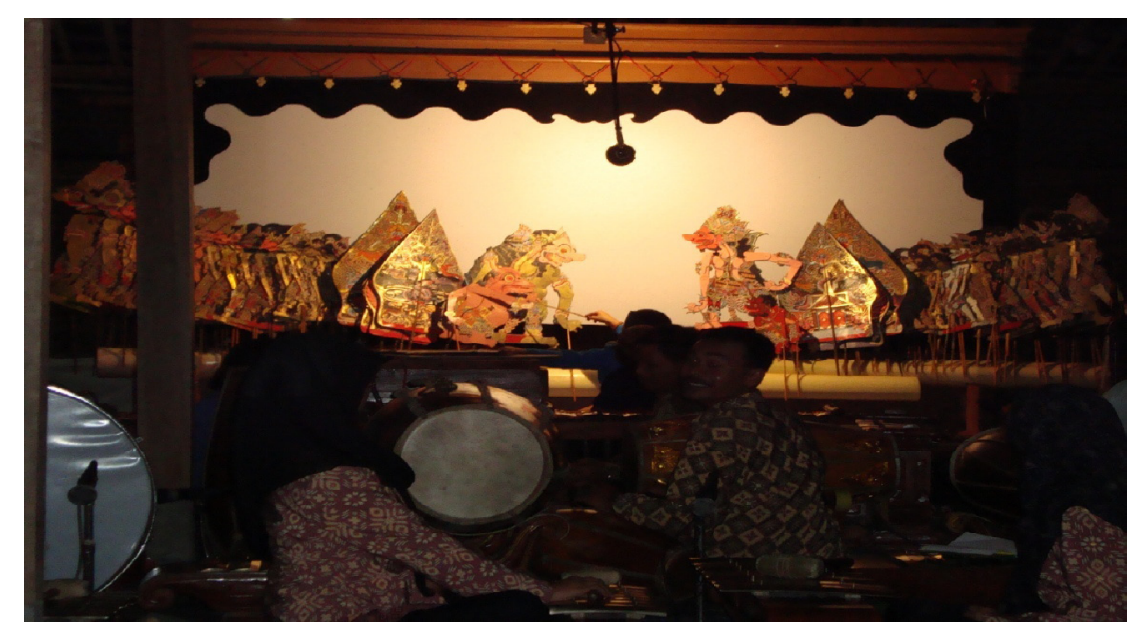

Gambar 3. Pementasan wayang kulit purwa oleh dalang anak Adam Gifari, menggunakan satu set wayang ukuran padhalangan disisipi wayang ukuran kecil koleksi Padepokan Seni Sarotama, di Ngringo, Jaten, Karanganyar (Foto: Junaidi, 2008).

\section{Ukuran Wayang}

Ukuran wayang bagi sebagian dalang anak ditemukan persoalan, sehingga dilakukan pengurangan lebar dan tingginya boneka wayang. Pengurangan bersifat menyeluruh dan terbatas. Pengurangan menyeluruh dilakukan pada semua ukuran wayang mulai dari ukuran paling kecil sampai yang paling besar, sedangkan pengurangan terbatas hanya dilakukan untuk wayang ukuran magak ke atas sampai ukuran paling gedhé atau seukuran Gatutkaca sampai Buta Raton. Pengurangan dimaksudkan untuk memperingan tugas dalang anak, karena ditemukan beberapa dalang anak yang merasa keberatan memainkan tokoh wayang ukuran tertentu, yaitu ukuran magak, gedhé, dan paling gedhé. Untuk itu, maka dibuatkan boneka wayang ukuran lebih kecil dari yang sudah ada agar lebih ringan. Contohnya wayang Buta Raton dibuat seukuran Boma yang mempunyai tinggi \pm tiga kilan lebih satu geblok atau sekitar 70 centimeter. Penampilan wayang dengan ukuran campuran seperti ini menjadi tidak mungguh (tidak logis) dalam pemahaman ukuran wayang.

Berdasarkan realitas ini, maka diperlukan penyesuaian ukuran wayang satu set yang diharapkan sesuai dengan kemampuan anak atau disebut wayang kulit purwa padhalangan anak. Maksudnya seperangkat boneka wayang kulit purwa khusus untuk dalang anak. Berhubung dari ukuran magak ke ukuran gedhé terdapat interval agak jauh yakni antara satu kilan atau sekitar 23 centimeter dan dari gedhé ke paling gedhé \pm satu kilan satu setengah nyariatau sekitar 26 centimeter, maka lebih efektifnya dibuat jarak yang agak pendek. Guna menemukan ukuran yang logis atau mungguh, maka dari ukuran magak sampai paling cilik juga dikurangi dengan interval yang lebih sedikit, tetapi masih lebih besar dibanding dengan wayang kidangkencanan. Dengan adanya satu set boneka wayang kulit purwa format padhalangan anak secara khusus, maka sinkronisasi ukuran dan aktivitas pertunjukan wayang oleh dalang anak dapat tercapai sesuai dengan tingkat kemampuannya.

Lebih jelasnya dipaparkan tentang perkiraan berbagai macam ukuran boneka wayang kulit purwa yang dianggap sesuai untuk dalang anak yakni: ukuran paling gedhé tinggi \pm tiga kilan satu geblok atau sekitar 70 centimeter, ukuran gedhé \pm dua kilan satu cengkang atau sekitar 57 centimeter, ukuran magak \pm dua kilan satu geblok atau sekitar 50 centimeter, tanggung \pm dua kilan atau sekitar 43 centimeter, ukuran sedheng \pm satu kilan lebih satu cengkang atau sekitar 39 centimeter, ukuran cilik \pm satu kilan lebih satu geblok dan lebih satu nyari atau sekitar 34 centimeter, dan ukuran paling cilik \pm satu kilan lebih tiga nyari atau sekitar 26 centimeter. Dengan demikian, maka selisih antar ukuran dari paling cilik ke cilik sekitar 6 centimeter, dari cilik ke sedheng sekitar 5 centimeter, dari sedheng ke tanggung sekitar 4 centimeter, dari tanggung ke magak sekitar 7 centimeter, dari magak ke gedhé sekitar 7 centimeter, dan dari gedhé ke paling gedhé sekitar 13 centimeter. Lebih jelasnya dapat ditampilkan perkiraan ukuran boneka wayang kulit purwa padhalangan untuk dalang anak dalam tabel berikut. 
Tabel 3. Ukuran wayang anak.

\begin{tabular}{lll}
\hline No. & Ukuran jenis & Ukuran tinggi sekitar \\
\hline 1. & Paling gedhél sak ButaRaton & 70 centimeter \\
2. & Gedhél sak Werkudara & 57 centimeter \\
3. & Magaklsak Gathutkaca & 50 centimeter \\
4. & Tanggung/ sak Setyaki & 43 centimeter \\
5. & Sedheng/sak Abimanyu & 39 centimeter \\
6. & Cilik/ sak Srikandhi & 34 centimeter \\
7 & Paling cilik/sak Bayèn & 26 centimeter \\
\hline
\end{tabular}

Wayang untuk dalang anak perlu ditambah tokoh-tokoh berusia muda dan anak-anak (putran) baik laki-laki dan perempuan. Selama ini boneka wayang kulit purwa yang ada lebih didominasi oleh tokoh berusia dewasa dan tua. Bertambahnya tokoh wayang muda dan anakanak, maka aktualisasi dalang anak terhadap wayang dapat tercapai maksimal, karena bonekaboneka wayang yang ditampilkannya lebih sesuai dengan perkembangan fisik dan jiwanya, yaitu fisik dan jiwa anak-anak. Tentu saja hal ini harus didukung dengan penampilan lakon-lakon yang bertema kekanakan, agar terjadi sinkronisasi antara tokoh, cerita, dan boneka wayangnya.

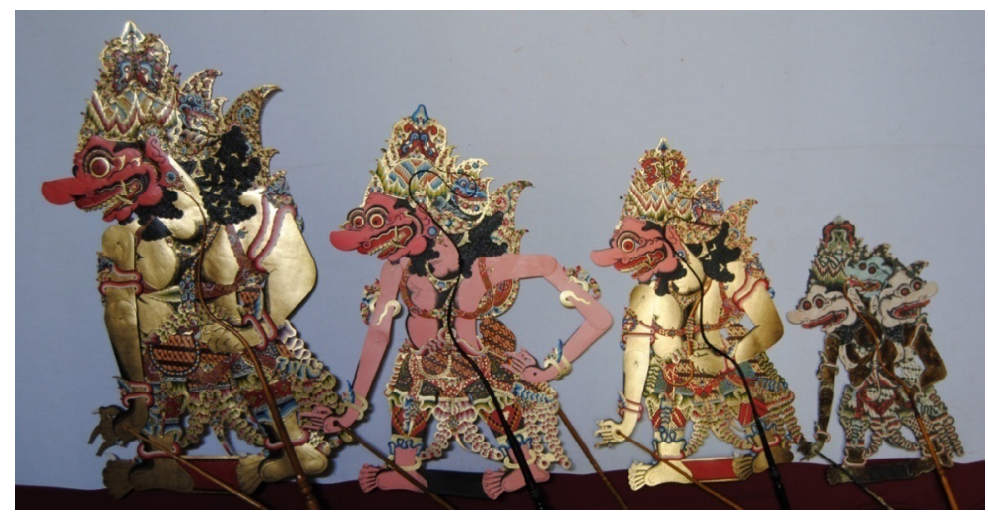

Gambar 7. Perbandingan wayang ukuran paling besar Buta Raton jenis wayang padhalangan (kiri), padhalangan dikecilkan (kedua dari kiri) wayang kidangkencanan (ketiga dari kiri), dan wayang kaper (kanan) (Foto: Junaidi, 2009).

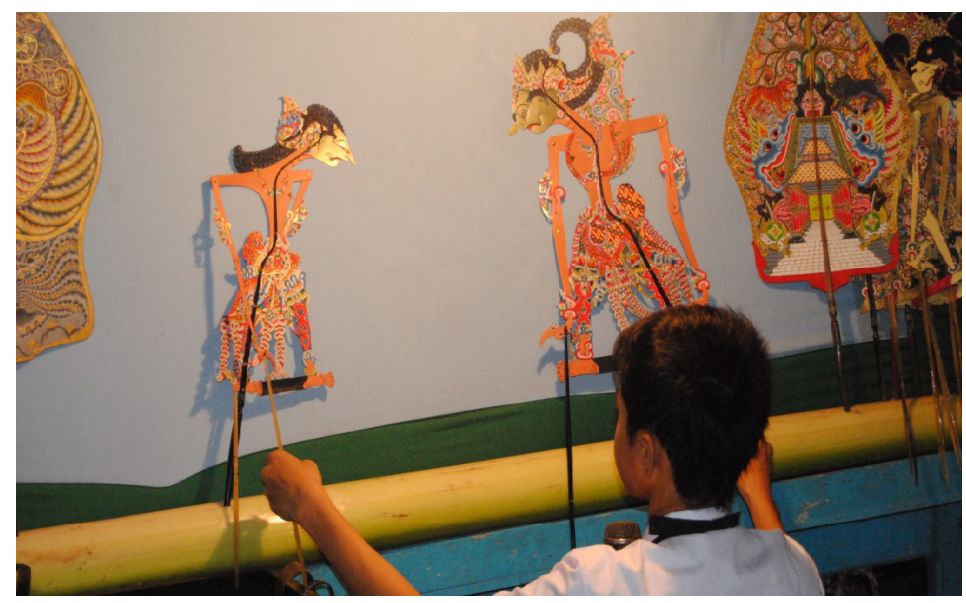

Gambar 9. Contoh wayang berusia muda bernama Abimanyu (kiri) dan Gatutkaca (kanan), koleksi Junaidi (Foto: Junaidi, 2010). 


\section{Penutup}

Berdasarkan pembahasan lakon dan wayang, tersebut di atas, maka dapat disimpulkan bahwa pakeliran oleh dalang anak merupakan model seni pertunjukan wayang kulit purwa yang bersifat profan dan non komersial, dan berfungsi untuk pembelajaran, apresiasi, dan upaya membangun kontinuitas seni pewayangan kepada generasi penerus, yakni dimulai dari generasi tua yang kemudian diteruskan oleh generasi muda. Anakanak merupakan aset sumberdaya manusia di masa datang, memiliki tanggung jawab untuk meneruskan budaya tradisi yang telah dibangun dan diwariskan oleh generasi sebelumnya, sehingga keberlangsungan kehidupan suatu budaya sangat ditentukan oleh penerima warisan tersebut.

\section{Kepustakaan}

Gustami. 2000. Studi Komparatif Gaya Seni YogyaSolo. Yogyakarta: Yayasan Untuk Indonesia.

Hurlock, Elisabeth B. 2010. Perkembangan Anak. Jilid 1-2. Jakarta: Erlangga.

Nojowirongko, M.Ng., Atmotjendono. 1960. Serat Tuntunan Pedalangan, jilid I-IV.
Djogdjakarta: Tjabang Bagian Bahasa, Djawatan Kebudajaan, Departemen P.P. dan K.

Sarwono, Sarlito Wirawan. 2005. Psikologi Remaja. Jakarta: PT Raja Grafindo Persada.

Sastroamidjojo, Seno. 1964. Renungan Tentang Pertunjukan Wayang Kulit. Jakarta: Kinta Jakarta.

Soetarno. 2005. Pertunjukan Wayang \& Makna Simbolis. Surakarta: STSI Press.

Suyanto, ed. 2007. Teori Pedalangan: Bunga Rampai Elemen-Elemen Dasar Pakeliran. Surakarta: ISI Surakarta dan Percetakan CV. Saka Production.

Zulkifli. 2006. Psikologi Perkembangan. Bandung: PT. Remaja Rosdakarya.

\section{Informan}

Anggit Laras Prabowo (9 tahun), dalang anak tinggal di Desa Tunggulreja Jumantono, Matesih, Karanganyar, Surakarta.

Doni Siswanto (12 tahun), dalang anak tinggal di Pakahan, Jogonalan, Klaten. 